\title{
A Case of Ventricular Fibrillation in a Frail Patient with Chronic Obstructive Pulmonary Disease, Obstructive Sleep Apnea Syndrome, and Electrolytic Disorder
}

\author{
Nicola Marchitto ${ }^{a}$ Monica Mauti $^{b}$ Simona Andreozzi ${ }^{c}$ Alberto Pannozzi ${ }^{b}$ \\ Serenella G. Dalmaso ${ }^{\text {a }}$ Gianfranco Raimondi ${ }^{d}$ \\ ${ }^{a}$ Department of Internal Medicine, Alfredo Fiorini Hospital, Terracina, Italy; b Nursing School, "La Sapienza" \\ University, Rome, Italy; ${ }^{C}$ Faculty of Medicine and Surgery, "La Sapienza" University, Rome, Italy; ${ }^{\text {d}}$ Department of \\ Medical and Surgical Sciences and Biotechnologies, "La Sapienza" University, Rome, Italy
}

\section{Keywords}

Chronic obstructive pulmonary disease $\cdot$ Ventricular fibrillation · Cardiovascular risk · Frailty · Obstructive sleep apnea syndrome $\cdot$ Electrolytic disorders

\begin{abstract}
Chronic obstructive pulmonary disease (COPD) is associated with an increased cardiovascular risk, although the pathophysiological mechanisms responsible for this interdependence are not completely known. For instance, the increased sympathetic activity may be implied. The severity of COPD correlates with various arrhythmic manifestations such as atrial fibrillation, atrial flutter, and either sustained or nonsustained ventricular tachycardia. COPD and obstructive sleep apnea syndrome may increase the overall cardiovascular risk, especially in elderly patients. Additionally, electrolytic disorders may precipitate cardiac rhythm disturbances and thus cause important arrhythmic consequences such as ventricular fibrillation, as reported in our clinical case. We discuss here the possible treatment of this association of pathological conditions on the basis of a single case we have successfully treated, and provide a brief review of the available literature regarding cardiovascular comorbidities in COPD patients.
\end{abstract}

(c) 2018 S. Karger AG, Basel

\section{KARGER}

() 2018 S. Karger AG, Basel

E-Mail karger@karger.com

www.karger.com/res

\section{Introduction}

The correlation between respiratory disease and increased cardiovascular risk, mainly secondary to a neurovegetative dystonia with orthosympathetic system imbalance, is well established [1]. Chronic obstructive pulmonary disease (COPD) is a common comorbidity complicating the hospital course of patients experiencing cardiovascular disorders, especially heart failure. Pharmacological strategies aim to reduce exacerbations and control symptoms in order to improve the overall quality of life of COPD patients.

We report our clinical experience of a case of ventricular fibrillation in a frail patient with COPD and electrolyte disorder secondary to gastroenteric disease and present a brief review of the available literature.

\section{Case Description}

An 82-year-old man came to our attention in March 2015 with diarrhea due to gastroenteritis which appeared resistant to pharmacological treatment. His medical history revealed several comorbidities, such as COPD, congestive heart failure secondary to ischemic heart disease, with chronic pleural effusion and perma- 


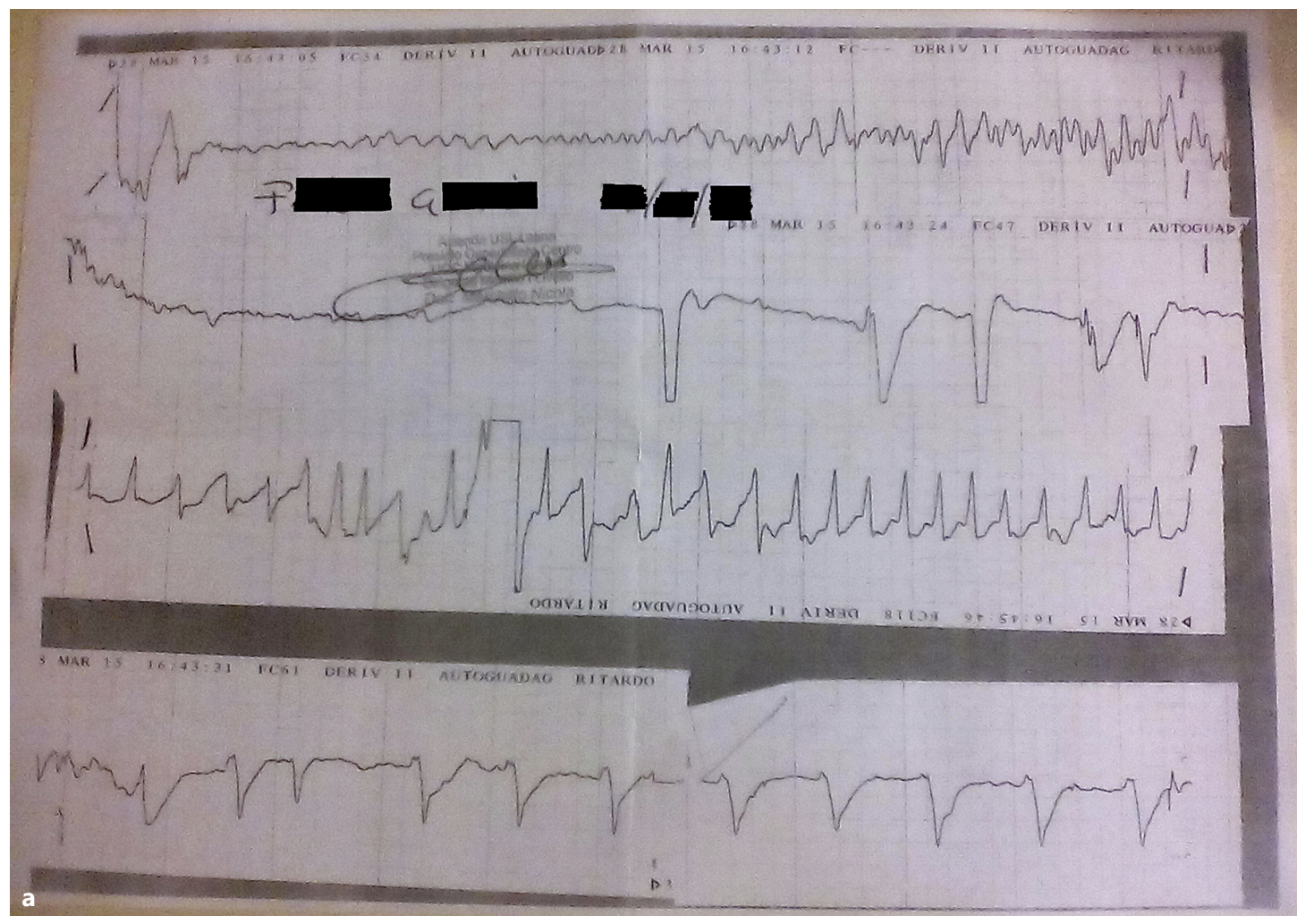

\section{$J \operatorname{sen} t 6$}

Susto Nowiters Anster Rasporto Aato

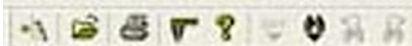

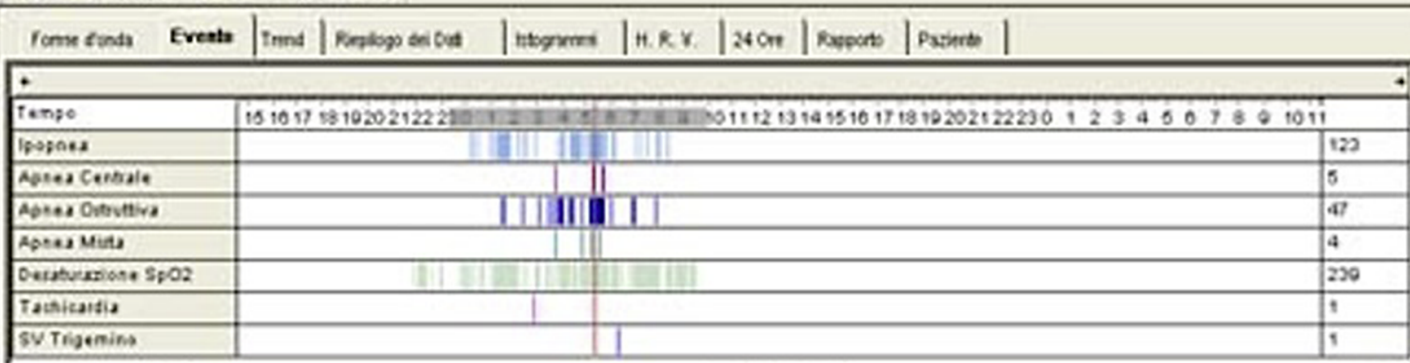

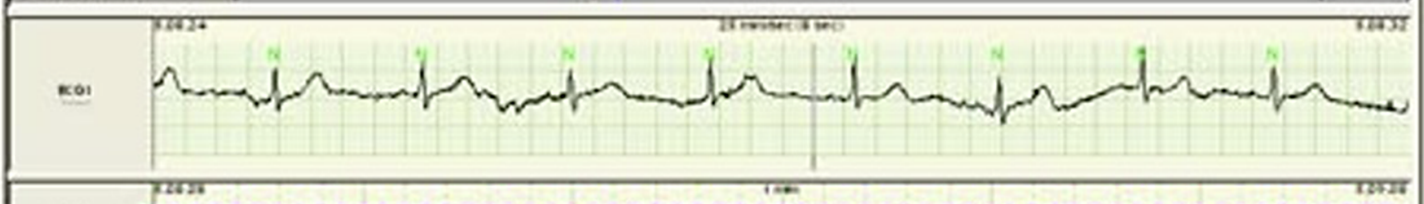

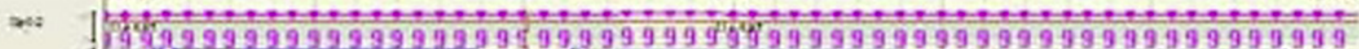

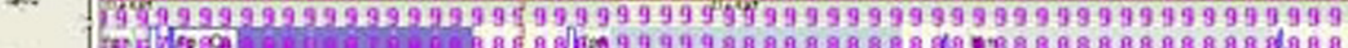

w. Fof

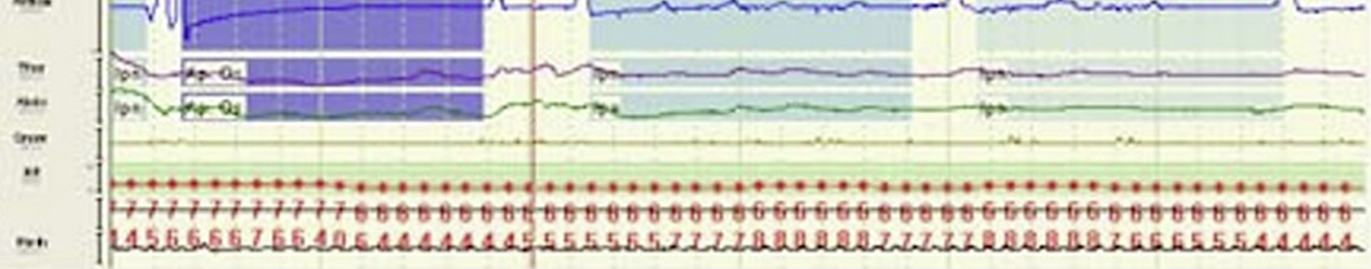

b Pronko

Fig. 1. a, b Continuous ECG trace during ventricular fibrillation and subsequent treatment with DC shock. 
Table 1. Laboratory tests of the patient over the course of his hospitalization

\begin{tabular}{lllc}
\hline Laboratory test & Emergency room & Internal medicine ward & Reference value \\
\hline Potassium, mEq/L & 2.3 & 3.9 & $3.5-5.2$ \\
Creatinine, mg/dL & 3.25 & 2.92 & $0.5-1.1$ \\
pH & 7.31 & 7.32 & $7.38-7.42$ \\
$\mathrm{PCO}_{2}, \mathrm{~mm} \mathrm{Hg}$ & 41.6 & 41.1 & $34-46$ \\
$\mathrm{PO}_{2}, \mathrm{~mm} \mathrm{Hg}$ & 67 & 167 & $80-100$ \\
$\mathrm{HCO}_{3}, \mathrm{mmol} / \mathrm{L}$ & 18.5 & 24.3 & $22-26$ \\
\hline
\end{tabular}

nent atrial fibrillation, chronic kidney disease, diabetes mellitus, and low-mobility syndrome.

Due to markedly reduced potassium plasma levels (Table 1), the patient received electrolyte supplementation with $40 \mathrm{mEq}$ of $\mathrm{KCl}$ in saline solution twice per day; additionally, aerosol therapy with ipratropium bromide 15 drops, beclomethasone 15 drops, and salbutamol 15 drops b.i.d. was instituted; large-spectrum antibiotic therapy for intestinal disease and diarrhea (cephalosporin and quinolone) was initiated. During hospitalization, an episode of new-onset high-frequency arrhythmia was recorded, with the subsequent need for continuous electrocardiographic monitoring. The patient remained conscious, although the ECG showed ventricular fibrillation immediately treated with a double $360 \mathrm{~J} \mathrm{DC}$ shock external defibrillation (the first shock was ineffective to restore a valid heart rhythm; Fig. 1). Amiodarone was thus initiated as antiarrhythmic prophylaxis and the patient was switched to the combination indacaterol/glycopyrronium, given its favorable safety profile [2]. Moreover, basal spirometry revealed a restrictive pattern, whereas polysomnographic examination showed obstructive sleep apnea syndrome with oxygen desaturation and concomitant supraventricular tachycardia. Of note, further cardiological investigations were planned in order to evaluate the feasibility of implanting an internal cardioverter defibrillator for secondary prevention of ventricular arrhythmias.

\section{Discussion}

The presence of several concomitant comorbidities makes it difficult to evaluate the real arrhythmic and cardiovascular risk of old patients with electrolytic disorders. In a recent paper, Konecny et al. [3] have highlighted the association of ventricular and supraventricular arrhythmic disturbances in COPD patients. Moreover, Men et al. [4] also underlined the importance of the association of heart conduction abnormalities (such as sinus bradycardia and supraventricular arrhythmias) and severe-to-moderate sleep apnea.

Cardiovascular comorbidities negatively impact the morbidity and mortality rates of COPD patients $[5,6]$, mainly due to the chronic proinflammatory state associated with these diseases, and the subsequent microcirculation disturbances $[7,8]$.

Ventricular Fibrillation in a Comorbid COPD Patient
Long-acting beta-agonists (LABA) and long-acting muscarinic antagonists (LAMA) are useful in controlling COPD symptoms and prevent/reduce COPD exacerbations requiring hospital admission [9]. Recently, a new combination drug formed of a LABA (indacaterol) and a LAMA (glycopyrronium) in a fixed association has been developed. This drug has demonstrated a synergistic effect of the two molecules in improving bronchodilation [10], and moreover it also seems to be safe in patients with cardiovascular comorbidities. No cardiovascular events were recorded in the SHINE study, evaluating this drug combination versus both each single drug compound and placebo, over a 26-week follow-up period [11].

\section{Conclusion}

COPD and obstructive sleep apnea may increase the cardiovascular risk profile of elderly patients. Moreover, electrolytic disorders may further raise the arrhythmic rate and thus precipitate a long-standing unstable condition in a frail patient with several comorbidities.

\section{Acknowledgement}

The authors are particularly grateful to Lino Marchitto, Carla Maria Maisano, and Federica Marchitto for useful discussions. The authors thank Luca Giacomelli, $\mathrm{PhD}$, for providing medical writing on behalf of Content Ed Net; this assistance was funded by Novartis Farma SpA.

\section{Financial Disclosure and Conflicts of Interest}

The authors have no conflicts of interest to declare. 


\section{References}

1 Konecny T, Park JY, Somers KR, Konecny D, Orban M, Soucek F, Parker KO, Scanlon PD, Asirvatham SJ, Brady PA, Rihal CS: Relationship of COPD to atrial and ventricular arrhythmias. Am J Cardiol 2014;114:272-277.

2 Matera MG, Rogliani P, Calzetta L, Cazzola M: Safety consideration with dual bronchodilator therapy in COPD: an update. Drug Saf 2016;39:501-508.

3 Konecny T, Somers KR, Park JY, John A, Orban M, Doshi R, Scanlon PD, Asirvatham SJ, Rihal CS, Brady PA: Chronic obstructive pulmonary disease as a risk factor for ventricular arrhythmias independent of left ventricular function. Heart Rhythm 2017, Epub ahead of print
4 Men XQ, Wang YK, Li J, Wei YQ, Xue C, Wang HQ: Nocturnal heart rhythm disorder in patients with obstructive sleep apnea syndrome (in Chinese). Zhonghua Yi Xue Za Zhi 2013;93:3655-3658.

5 Parissis JT, Andreoli C, Kadoglou N, et al: Differences in clinical characteristics, management and short-term outcome among acute heart failure patients with COPD and those without this comorbidity. Clin Res Cardiol 2014;103:733-741.

6 Anthonisen NR: The effects of a smoking cessation intervention on 14.5-year mortality: a randomized clinical trial. Ann Intern Med 2005; 142:233-239.

7 Sin DD: Why are patients with chronic obstructive pulmonary disease at increased risk of cardiovascular diseases? The potential role of systemic inflammation in chronic obstructive pulmonary disease. Circulation 2003;107: 1514-1519.
8 Maclay JD: Vascular dysfunction in chronic obstructive pulmonary disease. Am J Respir Crit Care Med 2009;180:513-520.

9 Wedzicha JA: Indacaterol-glycopyrronium versus salmeterol-fluticasone for COPD. N Engl J Med 2016;374:2222-2234.

10 Ficker JH: Role of dual bronchodilators in COPD: a review of the current evidence for indacaterol/glycopyrronium. Pulm Pharmacol Ther 2017;45:19-33.

11 Bateman ED: Dual bronchodilation with QVA149 versus single bronchodilator therapy: the SHINE study. Eur Respir J 2013;42: 1484-1494. 